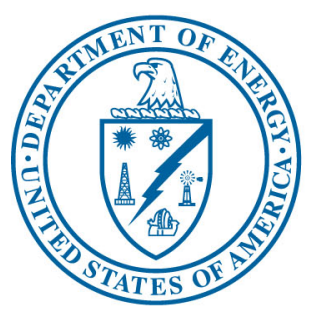

U.S. Department of Energy

Idaho Operations Office

Risk-Based Disposal Plan for PCB

Paint in the TRA Fluorinel Dissolution Process Mockup and Gamma

Facilities Canal

May 2008

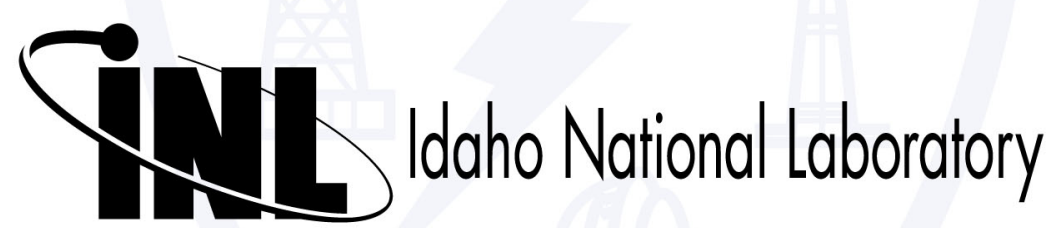




\section{Risk-Based Disposal Plan for PCB Paint in the TRA Fluorinel Dissolution Process Mockup and Gamma Facilities Canal}

May 2008 


\section{ABSTRACT}

This Toxic Substances Control Act Risk-Based Polychlorinated Biphenyl Disposal plan was developed for the Test Reactor Area Fluorinel Dissolution Process Mockup and Gamma Facilities Waste System, located in Building TRA-641 at the Reactor Technology Complex, Idaho National Laboratory Site, to address painted surfaces in the empty canal under 40 CFR 761.62(c) for paint, and under 40 CFR 761.61(c) for PCBs that may have penetrated into the concrete. The canal walls and floor will be painted with two coats of contrasting non-PCB paint and labeled as PCB. The canal is covered with open decking; the access grate is locked shut and signed to indicate PCB contamination in the canal. Access to the canal will require facility manager permission. Protective equipment for personnel and equipment entering the canal will be required. Waste from the canal, generated during ultimate Decontamination and Decommissioning, shall be managed and disposed as PCB Bulk Product Waste. 


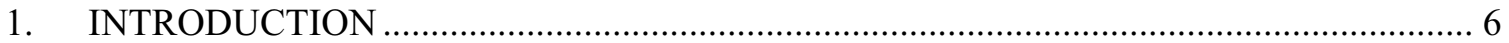

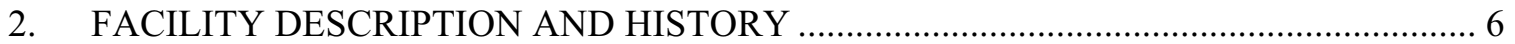

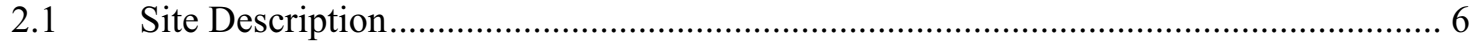

2.2 Gamma Facilities Use of the Canal and Waste Water Description and Operating History 6

2.3 Fluorinel Dissolution Process Mockup System Description and Operating History ..... 7

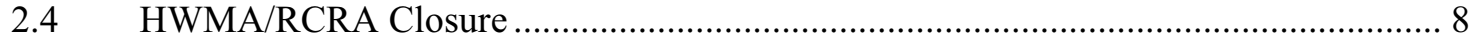

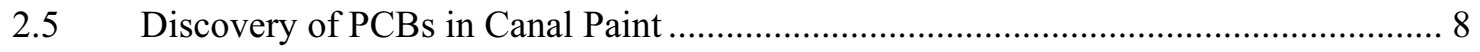

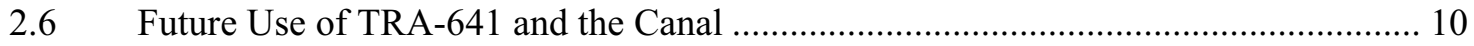

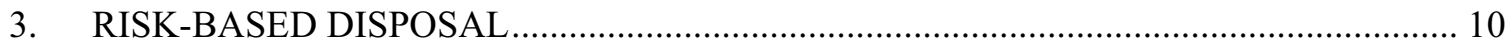

3.1 Goals of Risk-Based Disposal For Long-Term Storage............................................ 10

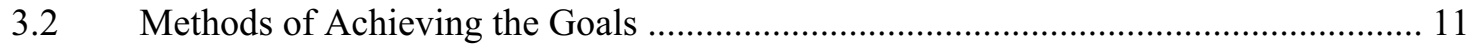

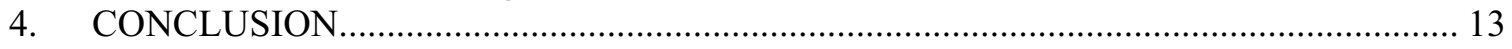

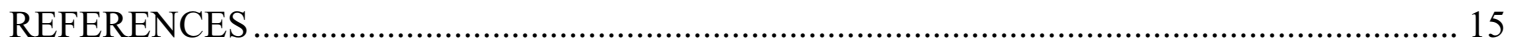




\section{Risk-Based Disposal Plan for PCB Paint in the TRA Fluorinel Dissolution Process Mockup and Gamma Facilities Canal}

\section{INTRODUCTION}

This Toxic Substances Control Act (TSCA) Risk-Based Disposal Plan has been prepared for the long-term storage pending final disposal of PCB applied paint and potentially contaminated concrete in Building TRA-641, located at the Test Reactor Area (TRA) Fluorinel Dissolution Process (FDP) Mockup and Gamma Facilities Waste System canal at the Reactor Technology Complex (RTC) (formerly TRA), Idaho National Laboratory (INL) Site. The regulatory citations are 40 CFR 761.62(c) for the PCB paint (PCB bulk product waste) on the walls and floor of the canal, and 40 CFR 761.61(c) for any PCBs that may have penetrated the concrete (PCB remediation waste).

This TSCA Risk-Based Disposal Plan includes a general description of the history and use of the building and the canal.

\section{FACILITY DESCRIPTION AND HISTORY}

\subsection{Site Description}

The INL Site encompasses approximately $890 \mathrm{mi}^{2}$ on the northern edge of the Eastern Snake River Plain in southeastern Idaho. The RTC (previously TRA) is situated on the south-central portion of the INL Site (see Figure 1) and occupies an enclosed and secured area.

\subsection{Gamma Facilities Use of the Canal and Waste Water Description and Operating History}

The Gamma Building (TRA-641) was originally constructed in 1955 to conduct gamma irradiation experiments using spent fuel elements from the Materials Test Reactor (Phillips 1957) in the TRA-641 canal. The spent fuel emitted gamma rays that had a penetrating power similar to $\mathrm{x}$-rays that could, among other things, kill pathogens. The variety of products irradiated included meat, grain, fruit, plastics, drugs, coal, gold, and diamonds (DOE-ID 2000). By 1971, the gamma irradiation experiments ended, all the radioactive components were removed from TRA-641, and the canal was drained and decontaminated (Rolfe and Wills 1984). The interior dimensions of the canal are approximately 40-ft long X 6-ft wide X 17-ft deep.

Between 1955 and 1971, warm (radioactive) wastewater generated from the irradiation experiments in TRA-641 was collected in two piping systems prior to being discharged from the building. The first system collected wastewater from the canal overflow weir (which also acted as the building floor drain) and the laboratory sinks and hood drains via the chemical drain line, 
which gravity-drained to the canal sump in the bottom of the pipe tunnel. A float-controlled sump pump discharged wastewater to the building discharge line.

The second TRA-641 warm wastewater piping system was used to discharge canal water. The canal wastewater piping consisted of piping from four canal floor drains to a common header in the pipe tunnel. The header utilized a 3-hp pump located in the pipe tunnel to discharge the canal water out the building warm waste discharge line.

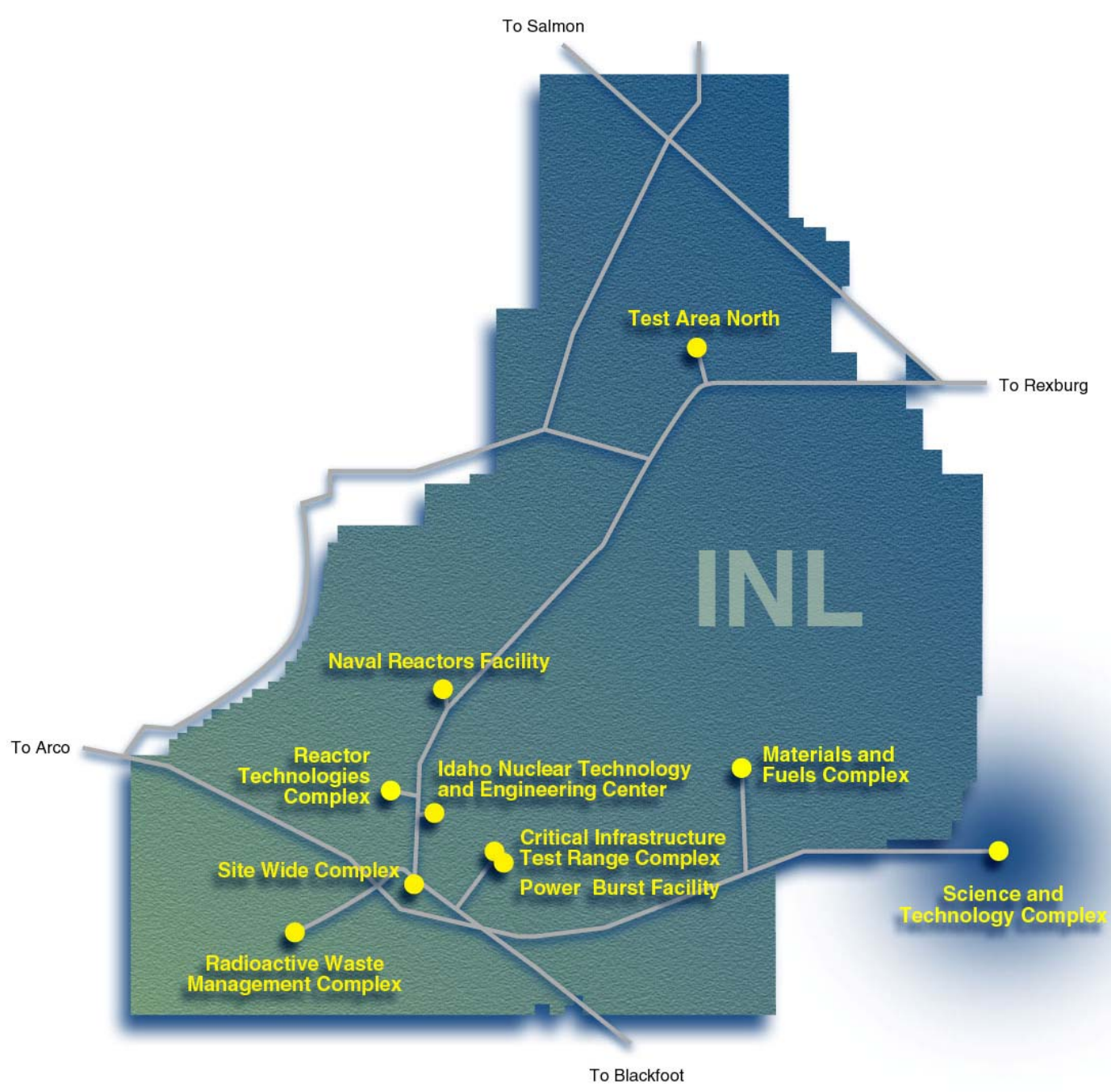

Figure 1. Map of the INL Site showing the location of the Reactor Technology Complex.

\subsection{Fluorinel Dissolution Process Mockup System Description and Operating History}

The Fuel Dissolution Process (FDP) mockup was a full-scale test platform for the FDP located at the Idaho Nuclear Technology and Engineering Center (INTEC). The mockup was designed for process experimentation, design testing, and determination of operational parameters. This 
mockup was built inside TRA-641 in 1975 to test various aspects of the dissolution process before project implementation, including flow characteristics during sparging (INEEL 2000).

The FDP modifications included the addition of a catch tank and a receiver tank in the bottom of the canal to collect liquid waste from the mockup experiments. In addition, the chemical drain line from the lab sinks and hood was rerouted from the canal sump to the receiver tank. The catch tank and receiver tank received waste from the FDP mockup experiment and the TRA Gamma Facility Off-Gas Scrubber System. The off-gas scrubber system was used to treat off-gas from both the glass melter and calcine pelletizer experiments.

Work on the FDP ended in 1984. Since then the canal has not been in use except for HWMA/RCRA Closure of a waste tank system from FDP experiments and removal of equipment in preparation for ultimate decontamination and decommissioning (D\&D). Closure under HWMA/RCRA was required because hazardous waste tanks were located in the canal.

\subsection{HWMA/RCRA Closure}

Various tanks and ancillary systems associated with FDP activities in the TRA-641 canal were recognized to have managed hazardous waste. These systems have been closed under the Idaho Hazardous Waste Management Act/Resource Conservation and Recovery Act (HWMA/RCRA) Voluntary Consent Order (VCO). The Closure Certification was submitted to the Idaho Department of Environmental Quality on Sept. 25, 2007. Closure activities removed, or verified removal of, all piping, tanks, and other equipment from the canal (Jason Associates, 2007).

\subsection{Discovery of PCBs in Canal Paint}

In preparation for ultimate D\&D of TRA-641, the paint from the canal walls and floor was sampled for a variety of contaminants, including PCBs. Sample results showed the paint contains approximately 4,500 ppm PCBs. The paint with PCBs is assumed to be original to the facility (constructed in 1955). Localized areas of the canal walls and floor show chipping paint. All chips have been collected and managed as PCB waste. While PCBs were identified as a hazardous constituent during the HWMA/RCRA Closure (DOE/ID, 2007), PCB paint was neither noted on any of the equipment removed during Closure, nor found above $49 \mathrm{ppm}$ on any of the equipment removed during Closure. The canal drain system (warm waste) last known use would have been to drain the canal (completed by 1971). The floor drains have been cleaned (augered and HEPA vacuumed) as part of an ongoing VCO milestone (documentation not submitted to Idaho DEQ yet) between the canal and pipe tunnel, all piping and the pump in the pipe tunnel were removed, blind flanges were installed on the piping in the pipe tunnel, and waste dispositioned as MLLW/PCB waste (no sampling was performed).

Downstream samples were taken from the Warm Waste drain system. Sample results show no PCBs above regulatory limits. For the cold waste system (HWMA/RCRA closed), PCBs were included as a Contaminant Of Concern during closure; rinsates were sampled for PCBs, and concentrations were below action levels established by Idaho DEQ. 


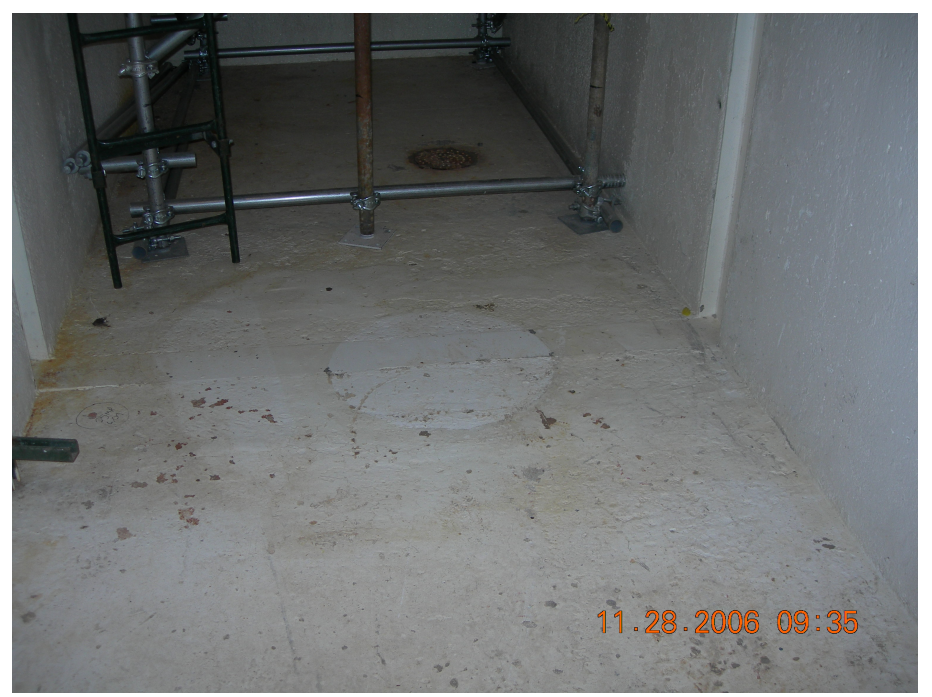

Photo 1 Canal Floor

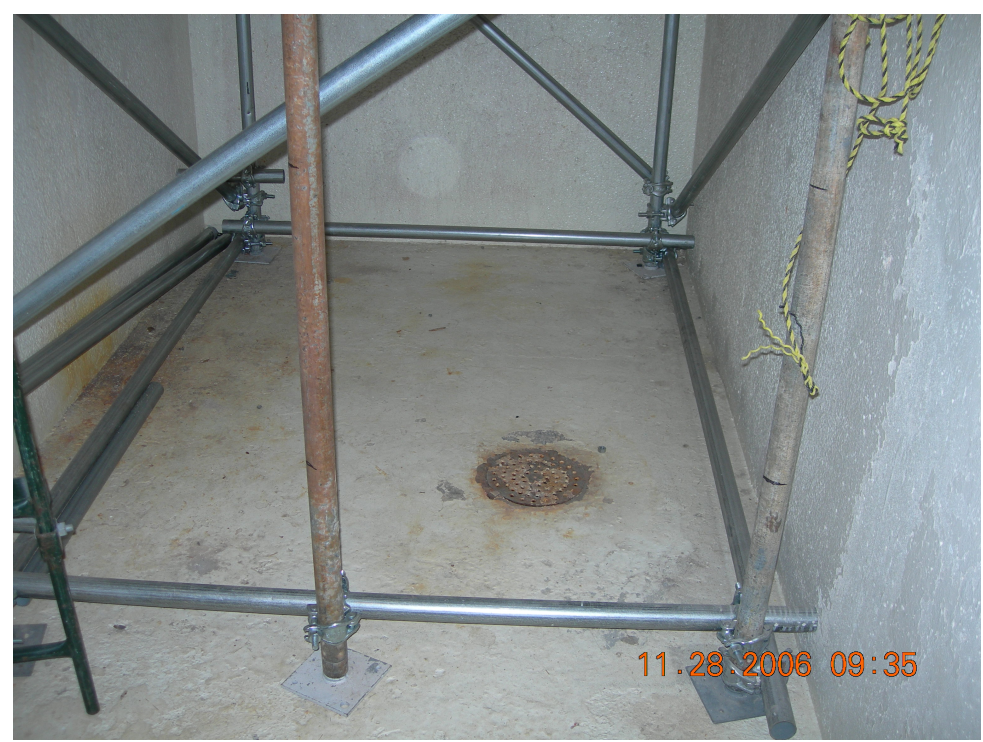

Photo 2 Canal Floor and Walls

An examination of the canal revealed that the color and type of paint found in the canal stops at the interior lip of the canal. The paint covering the top and exterior sides of the canal wall does not contain PCBs. 


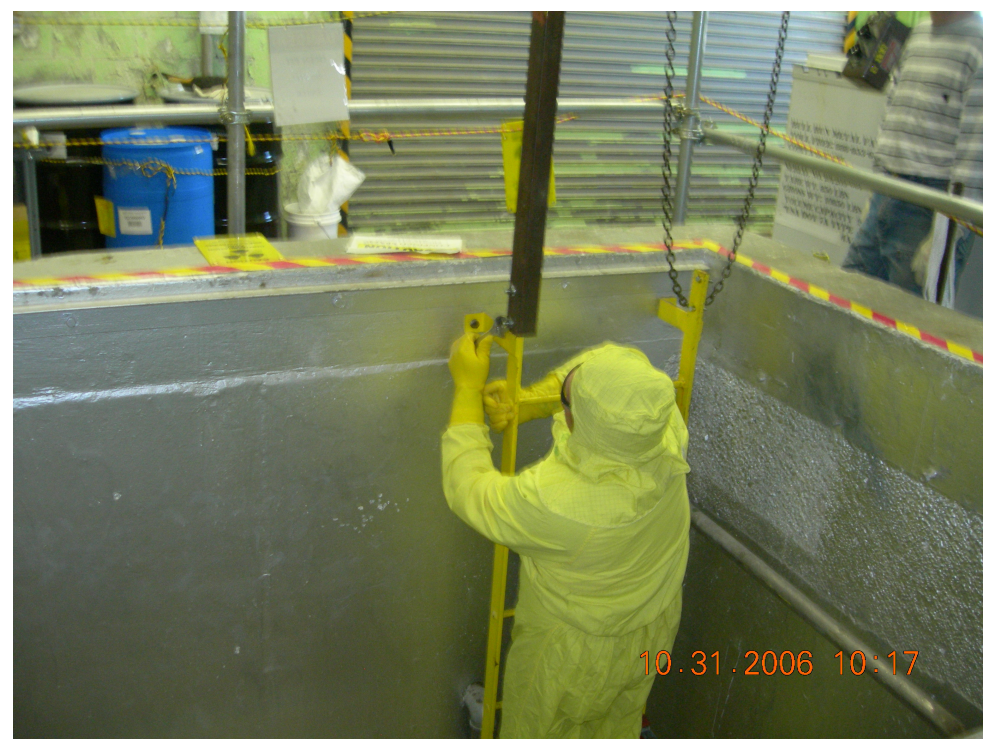

Photo 3 Canal Walls and Lip

\subsection{Future Use of TRA-641 and the Canal}

All equipment, such as scaffolding shown in the photos, has been removed from the canal. One foreseeable use for the canal is to conduct mock-up and practice using remote manipulation tools for a future task on a highly radioactive system. Equipment will be placed into the canal; personnel will generally remain outside the canal. Besides PCB contamination of paint in the canal, the canal is also a radioactive contamination zone; entry is also regarded as entry into a confined space.

Building TRA-641 is currently used as a workspace for crafts personnel such as pipefitters and welders. All work takes place outside of the canal. While a date has not yet been established, TRA-641 is expected to undergo D\&D.

\section{RISK-BASED DISPOSAL}

\subsection{Goals of Risk-Based Disposal for Long-Term Storage for Disposal}

The goals of the Risk-Based Disposal for long-term storage until final disposal through the D\&D process of PCB paint on the interior of the TR-641 canal are:

a. Minimize potential human exposure to the paint by taking steps to reduce opportunities for inhalation, ingestion, or skin exposure to the paint; and

b. Minimize potential environmental contamination by containing and controlling the paint during current use and future D\&D activities; and 
c. Perform D\&D of the canal such that PCBs subject to this RBDA do not pose an unreasonable risk to human health and the environment after D\&D.

\subsection{Methods of Achieving the Goals}

Several actions have been taken to minimize potential exposure to PCB paint in the TRA-641 canal. These are:

a. Paint chips have been collected and managed as PCB bulk product waste

b. Floor drains and pipe openings have been plugged.

c. The access to the grate covering the canal has been locked and marked to indicate PCB contamination in the canal.

d. The access to the grate covering the canal has been marked indicating that permission from the Facility Manager is required for entry.

Additional steps that will be taken as part of this Risk-Based Approval:

a. Any new paint chips will be removed from the floor of the canal using a vacuum equipped with a high-efficiency particulate filter. The chips will be managed as PCB Bulk Product Waste.

b. Prior to painting the canal walls and floor, samples of air from inside the canal will be taken and analyzed to verify the concentration of PCB is below safe work levels, as defined by OSHA or NIOSH. If safe work levels are exceeded, then painters will don appropriate respiratory protection in addition to standard PPE required to enter the canal for painting activities.

c. The floor and walls of the canal will be painted with two coats of paint in accordance with the requirements of 40 CFR 761.30(p)(1)(iii)(A)(1): "Two solvent resistant and water repellent coatings of contrasting colors to allow for a visual indication of wear through or loss of outer coating integrity". Each of the new coats will contrast with the current color of paint. The paint will be maintained in good condition.

d. The floors and wall of the newly-painted canal will be marked with the $\mathrm{M}_{\mathrm{L}}$ mark.

e. All doors to the building in which the canal is located will be marked with the $M_{L}$ mark.

f. Drawings of the building will be annotated to show the presence of PCB paint.

g. Personnel or equipment that may require entry to the canal will require personal protective equipment, such as gloves, impermeable footwear, Tyvek, or other coverings, as determined and identified by Safety and Industrial Hygiene personnel. The coverings will be managed based on the concentration of PCBs found on the material upon exit from the canal.

h. The canal will be inspected at least annually for the following: 1) deterioration or wear of paint; 2) presence and condition of signs on the building doors; 3) presence of a lock and access restriction signage on the canal access; and 4) presence and condition of $\mathrm{M}_{\mathrm{L}}$ marks at the canal access, on the canal walls, and on the doors to TRA-641. 
i. At the time of $\mathrm{D} \& \mathrm{D}$, the paint, metal, and concrete material comprising the canal walls and floor will be managed and disposed as PCB Bulk Product Waste and/or PCB Remediation Waste. Disposal may take place at the ICDF, or at a Subtitle C or D landfill.

j. The Department of Energy will submit a written report to EPA, no less than every five (5) years, detailing the condition of the canal, stating the current and expected future use of the canal, and the scheduled date for $\mathrm{D} \& \mathrm{D}$, if one has been established.

k. Upon D\&D of the TRA-641 Canal, possibly under the DOE CERCLA authority, the DOE will demonstrate to the EPA that the final site conditions meet the TSCA "no unreasonable risk" standard with respect to residual PCB contamination that might result from long-term storage authorized under this RBDA. Such demonstration may be included in the appropriate CERCLA documentation, such as a Final Record of Decision, or other written communication with EPA.

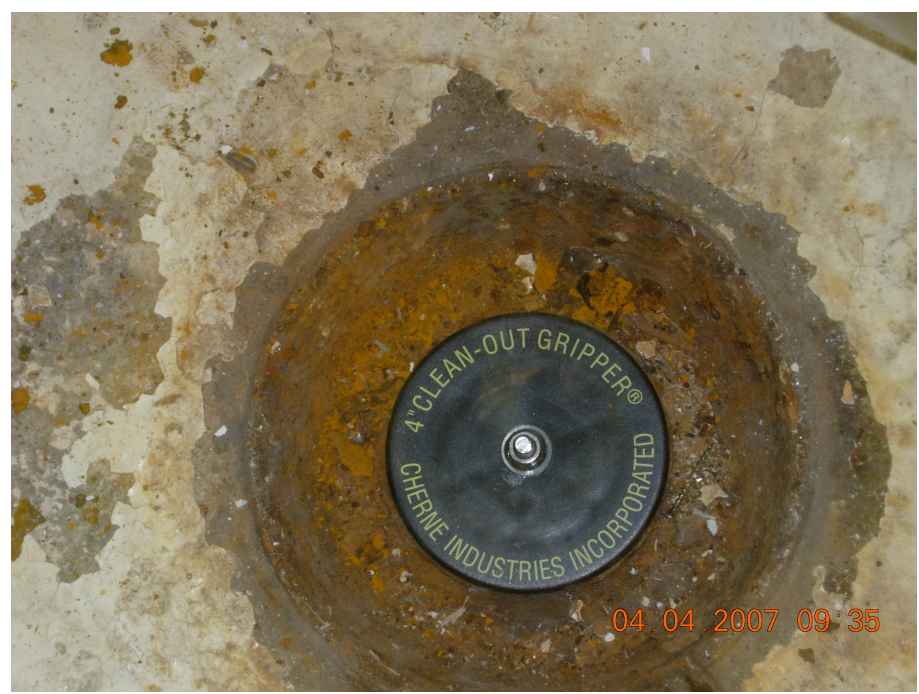

Photo 4 Plugged Floor Drain

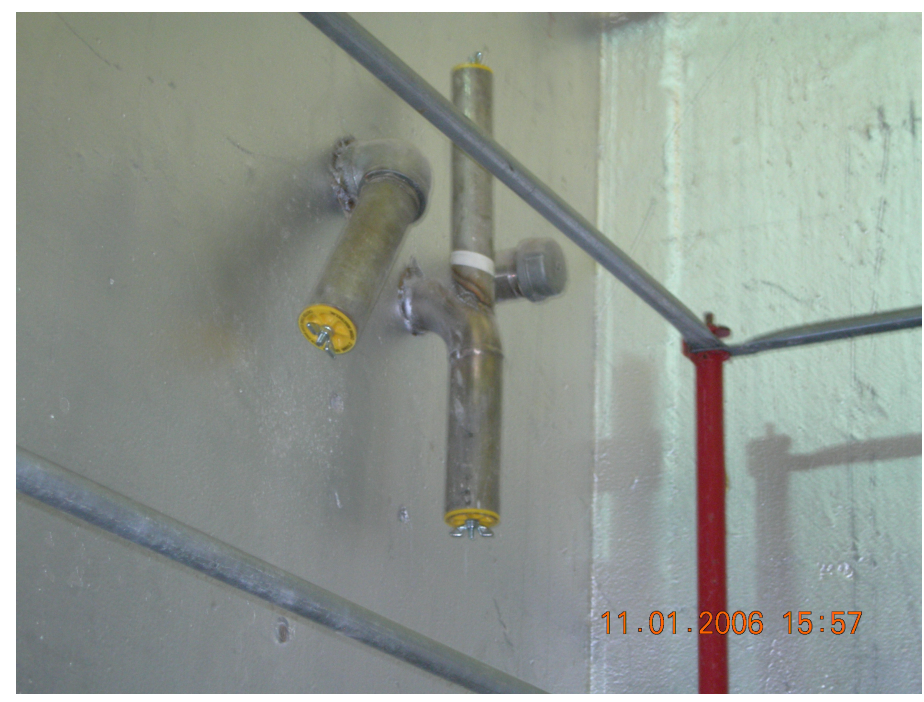

Photo 5 Plugged Pipes 


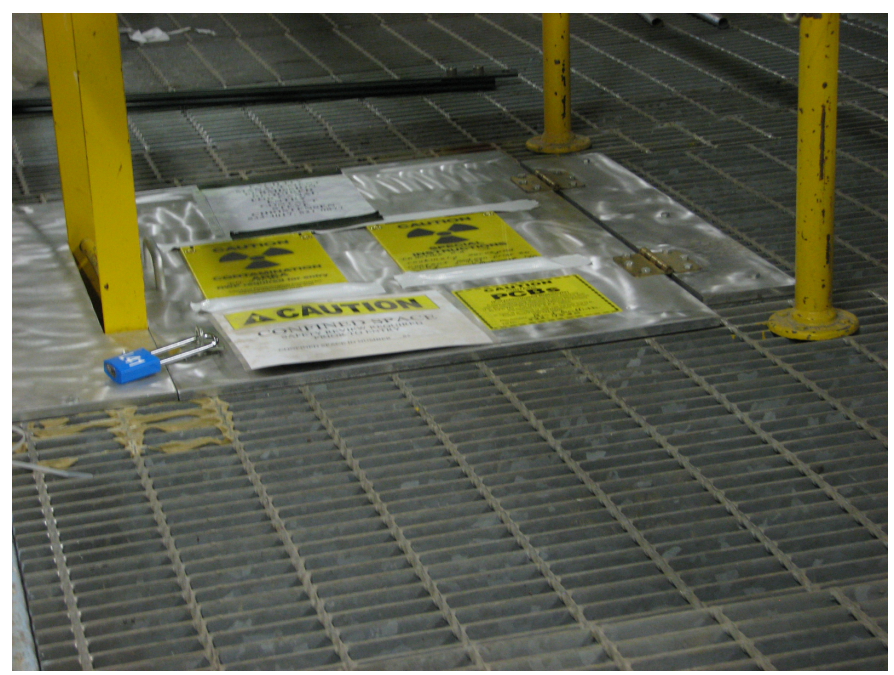

Photo 6 Grate Covers The Canal

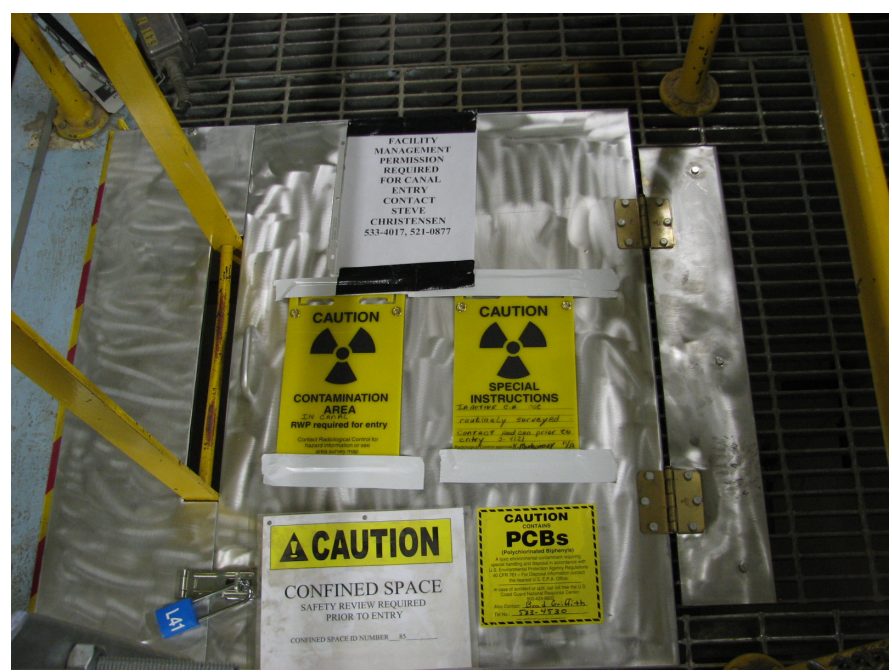

Photo 7 Canal Access Is Locked and Signed

\subsection{Protection of Human Health and the Environment}

It is believed that specific actions proposed under this RBDA application are sufficient to demonstrate that the proposed storage for disposal of PCBS in the TRA-641 canal does not pose an unreasonable risk of injury to human health or the environment during the remaining lifetime of the canal and after D\&D, meeting both the goals stated in Section 3.1 as well as the regulatory requirements found at 40 CFR $761.62(\mathrm{c})$.

\section{CONCLUSION}

The empty canal in Building TRA-641 is not in use and foreseen use is minimal and transient. It is expected the building will undergo D\&D sometime in the next 15 years. Entry to the canal is currently limited due to radioactive contamination and 
because it is a confined space. The presence of PCB paint will add a third limitation. While some paint on the walls and floor is chipping, the entire interior of the canal will be vacuumed with a high-efficiency filtered vacuum followed by painting with two layers of contrasting paint to prevent further chipping as well as prevent contact with the PCB paint.

It is submitted that these actions and precautions will minimize risk to human health and the environment by effectively containing and protecting PCB paint in the TRA641 canal. 


\section{REFERENCES}

40 CFR 761, "Polychlorinated Biphenyls (PCBs) Manufacturing, Processing, Distribution in Commerce, and Use Prohibitions," Code of Federal Regulations, Office of the Federal Register, as amended.

Phillips, 1957, "MTR Gamma Facility Operation Manual," Phillips Petroleum Co. - Atomic Energy Division, IDO-16423, December 1957.

DOE-ID, 2000, Proving the Principle: A History of the Idaho National Engineering and Environmental Laboratory, 1949-1999, DOE/ID-10799, 2000.

Rolfe, R. L., and E. L. Wills, 1984, Characterization of the Materials Testing Reactor, EG\&G Idaho, Inc., WM-F1-83-016, 1984.

INEEL, 2000, Characterization and Decision Analysis Report for Test Reactor Area Buildings 654 and 641, INEELIEXT-99-00902, Rev. 1, August 2000.

Jason Associates, 2007, Supporting Documentation for HWMA/RCRA Closure Certification of the TRA Fluorinel Dissolution Process Mockup and Gamma Facilities Waste System Voluntary Consent Order SITE-TANK-005 Tank System TRA-009, Jason Associates Corporation

DOE-ID, 2007, HWMA/RCRA Closure Plan for the TRA Fluorinel Dissolution Process Mockup and Gamma Facilities Waste System Voluntary Consent Order SITE-TANK-005 Tank System TRA-009, DOE/ID-11282, Rev. 1, January 2007 